\title{
Retraction Note: Geochemical characteristics of South China Sea based on random forest algorithm and Wushu teaching action simulation
}

\author{
Han Jianyun ${ }^{1}$
}

Published online: 29 November 2021

(c) Saudi Society for Geosciences 2021

Retraction Note: Arabian Journal of Geosciences (2021) 14: 1802 https://doi.org/10.1007/s12517-021-08182-0

The Editor-in-Chief and the Publisher have retracted this article because the content of this article is nonsensical. The peer review process was not carried out in accordance with the Publisher's peer review policy. The author has not responded to correspondence regarding this retraction.

The original article can be found online at https://doi.org/10.1007/ s12517-021-08182-0

1 Zhengzhou Institute of Technology, Zhengzhou 450000, Henan, China 